\title{
LOS DERECHOS LABORALES INESPECÍFICOS
}

\author{
MARIo Pasco COSMÓPOLIS \\ Pontificia Universidad Católica del Perú
}

\begin{abstract}
RESUMEN: En este trabajo el autor realiza un estudio de los derechos fundamentales inespecíficos dentro del Derecho Laboral. Parte describiéndoles como una categoría jurídica reciente dentro de la disciplina; establece su genealogía; los encuadra dentro del desarrollo que ha tenido la constitucionalización de las distintas ramas del derecho; culmina señalando sus características más propias, $y$, enunciando un catálogo de cuáles son los derechos inespecíficos.
\end{abstract}

Palabras clave: Derechos fundamentales, derechos inespecificos, eficacia horizontal, derecho al honor, no discriminación, intimidad, libertad de expresión, tutela judicial.

ABSTRACT: In this paper the author studies the non-specific fundamental rights in the Labor Law. He begins for describing them as a recent legal category in the discipline; establishes its descent; fits them in the development that has taken the constitutionalisation of the various branches of law; and ends by pointing their own characteristics, and stating a catalog of wich are the non-specific rights.

Key words: Fundamental rights, non-specific rights, horizontal efficacy, right to honor, non discrimination, intimacy, freedom of speech, judicial tutelage.

\section{INTRODUCCIÓN}

¡Derechos inespecíficos! Como en el caso de los contratos atípicos, la sola denominación revela que la más clara y directa definición de los mismos es en gran medida pleonástica, casi tautológica: derechos laborales inespecíficos son aquellos que no son específicos ${ }^{1}$.

Pero no se trata de categorías enfrentadas o excluyentes. Los derechos inespecíficos no se contraponen a los específicos sino que los completan, los complementan. ¿Qué son, entonces y en buena cuenta, los derechos inespecíficos?

Comencemos por recordar que tanto los grandes instrumentos internacionales en materia, sobre todo, de derechos humanos, cuanto las constituciones nacionales y las respectivas legislaciones suelen contener, y cada vez más asiduamente, un elenco nutrido de derechos laborales, reconocidos y expresados como tales; derechos como la limitación de la jornada de trabajo, el descanso diario, semanal y anual, la remuneración mínima, la protección contra el despido arbitrario y, naturalmente, los derechos colectivos: libertad sindical, negociación colectiva, huelga.

Todos ellos corresponden a los trabajadores (y solo a ellos) en su calidad de tales, vale decir, por ser trabajadores.

\footnotetext{
Catedrático principal de la Pontificia Universidad Católica del Perú. Ex presidente de la Academia Iberoamericana de Derecho del Trabajo y de la Seguridad Social. Ex ministro de Trabajo y Promoción del Empleo de Perú.

1 Recordar la célebre definición de Efrén Córdova en su ponencia sobre contratos atípicos al XI Congreso Internacional de la SIDTSS (Caracas, 1985): son atípicos los contratos que no son típicos, para de allí, a partir de la definición de los contratos típicos, identificar a los atípicos.
} 
¿Son esos, acaso, los únicos derechos que les corresponden? ¿No son los trabajadores además y primigeniamente ciudadanos? ¿No les corresponden los derechos que corresponden a todos los ciudadanos? La respuesta obvia es que sí, ¡claro que les corresponden!

Pues bien, muchos de esos derechos como ciudadanos se ejercen dentro de la relación de trabajo; es decir, son también derechos laborales, aunque no específicamente tales.

El derecho a la igualdad, a la no discriminación, a la libertad de expresión, ¿podrían ser negados al trabajador en el seno de la relación con su empleador? Ciertamente que no.

Es más, sucede que a veces les son reconocidos doblemente: como ciudadanos y como trabajadores. Así acontece, sin más, con derechos como la igualdad o la no discriminación ${ }^{2}$.

Sin embargo, aquellos derechos les pertenecen por ser ciudadanos, no por ser trabajadores. Son derechos laborales no exclusiva o específicamente laborales.

Se reconoce pacíficamente a Manuel Carlos Palomeque como el estudioso que así los denominó. No es que él los creara o los descubriera, sino que fue el primero en catalogarlos como derechos laborales inespecíficos, y los definió así: "Son derechos atribuidos con carácter general a los ciudadanos que, al propio tiempo, son trabajadores y, por lo tanto, se convierten en verdaderos derechos laborales por razón del sujeto y de la naturaleza de la relación jurídica en que se hacen valer, en derechos constitucionales laborales inespecifícos" 3 .

Veamos la historia completa, al menos en sus rasgos esenciales.

\section{LOS DERECHOS FUNDAMENTALES}

En su moderna concepción, los derechos fundamentales suelen ser identificados con los derechos humanos. En realidad, se trata de derechos humanos fundamentales, algunos de los cuales, en lo que más nos concierne, corresponden a la esfera de lo laboral y social.

$\mathrm{La}$ incorporación de los derechos sociales dentro del catálogo de los derechos humanos y de los derechos fundamentales corresponde históricamente a la aparición del denominado Estado social, cuyos rasgos definitorios, como evolución y por comparación con el Estado liberal, son descritos por García Pelayo:

“(...) mientras que el Estado tradicional se sustentaba en la justicia conmutativa, el Estado Social se sustenta en la justicia distributiva; mientras que el primero asignaba derechos sin mención de contenido, el segundo distribuye bienes jurídicos de contenido material; [...] mientras que el uno se limitaba a asegurar la justicia legal formal, el otro se extiende a la justicia legal material. Allí se trataba de un Estado cuya idea se realiza por la inhibición, aquí se trata de un Estado que se realiza por su acción en forma de prestaciones sociales, dirección económica y distribución del producto nacional"4.

\footnotetext{
2 Inclusive la libertad de asociación, aunque la libertad sindical sea en realidad de una entidad distinta a la mera asociatividad.

3 Palomeque, Manuel Carlos y Álvarez de la Rosa, M. Derecho del Trabajo. Madrid, España: Centro de Estudios Ramón Aceres, $9^{a}$ edición, 2001, p. 148.

4 Citado por Blancas Bustamante, Carlos. "La Constitución de 1979 y el Derecho del Trabajo", en: Revista Derecho, $\mathrm{n}^{\circ}$ 36, diciembre 1982, Lima, Perú, p. 11.
} 
Los derechos sociales son bautizados por algunos como "derechos humanos de segunda generación", dada su aparición en un segundo momento histórico, y "no estar referidos a la tutela de la esfera de libertad del individuo, sino al logro de la igualdad real o material y de la justicia social"'.

Dentro de los derechos sociales, a su vez, se encuadran los derechos propiamente laborales. Hay derechos fundamentales que no son laborales y derechos laborales que no son fundamentales; existen también, obviamente, derechos fundamentales que son laborales o sea derechos laborales que son también derechos humanos fundamentales. Como señala Plá Rodríguez,

"Lo importante es que esa incorporación de los derechos sociales en el elenco de los derechos humanos representó un avance considerable en la evolución de los conceptos. Supuso que en la conciencia de la gente no sólo se le debe garantizar su libertad y su seguridad individual, sino también debe asegurarse un nivel mínimo de bienestar"6.

"En ese marco -dice Barbagelata7-, la doctrina y la jurisprudencia constitucional han llegado también a aceptar la integración de todos los principios y normas sobre derechos humanos, cualquiera sea su fuente, en un bloque de la más alta jerarquía y fuerza normativa, tanto en el ordenamiento interno, como en el internacional. Tal bloque de constitucionalidad de los derechos humanos representa la superación de la antigua disputa entre monismo y dualismo y ha abierto el camino hacia el reconocimiento de un derecho de los derechos humanos, supralegal y supraconstitucional, que (...)no es ya meramente interno o internacional, sino universal".

Encarnan el moderno jus cogens, normas de orden público internacional que representan "el corazón del sistema jurídico de los derechos humanos", y cuyas notas características, según Ermida Uriarte ${ }^{8}$, son que: a) Obligan a todos los estados, independientemente de ratificaciones o cualquier otra forma de reconocimiento nacional; b) tienen efecto erga omnes, en cuanto no se dirigen solo a los Gobiernos, sino también a los individuos; c) pueden ser reclamados por cualquier persona o Estado, aun al margen de todo vínculo convencional o ratificación; d) son universales y no internacionales en el sentido tradicional de esta expresión; e) poseen multiplicidad de fuentes.

Campo en proceso de definición es la identificación de esos derechos, ya que "no existe acuerdo en la doctrina laboralista sobre los derechos laborales que deben ser considerados como derechos fundamentales"9.

\footnotetext{
5 Blancas Bustamante, Carlos. "Estado Social, Constitución y Derechos Fundamentales", en: Constitución, Trabajo y Seguridad Social. Lima, Perú: ADEC-ATC, 1994, p. 27.

6 Plá Rodrfguez, Américo. "Los derechos humanos y el derecho del trabajo", en: Debate Laboral, nº 6, 1990, p.15.

7 BARBAGELATA, Héctor Hugo. "El bloque de constitucionalidad de los derechos humanos laborales", en: VV.AA. El trabajo y la Constitución. Estudios en homenaje al Profesor Alonso Olea. Madrid, España: AIDTSS, Ministerio de Trabajo y Asuntos Sociales, 2003, p. 365.

8 Citado por BARBAGElATA, Héctor Hugo, op. cit. (n. 7.), p. 375.

9 Carrillo Calle, Martín. "Los derechos laborales fundamentales: Normas Mínimas Internacionales", en: Constitución, Trabajo y Seguridad Social. Lima, Perú: ADEC-ATC, 1994, p.42.
} 
Sin embargo, la configuración de un amplio catálogo de derechos laborales -fundamentales y legales- que determinan un marco de protección del trabajador, con la consiguiente limitación del poder del empleador, no agota la cuestión relativa al ejercicio de los derechos fundamentales del trabajador en la empresa, en la medida que sus derechos laborales -es decir, aquellos cuya titularidad supone la condición de trabajador- no constituyen la totalidad de sus derechos, o sea, no comprenden aquellos que posee como persona o ciudadano.

La respuesta tradicional ha consistido en separar radicalmente ambos grupos de derechos, considerando que el trabajador ejerce la titularidad de sus derechos laborales en la empresa, en el seno de las relaciones laborales, y la titularidad de sus derechos como persona y ciudadano, fuera de la empresa, en su relación con el Estado y la sociedad. En otras palabras, en el seno de las relaciones laborales -en concreto, en la relación con su empleador-, el trabajador no sería titular de derechos fundamentales no laborales, ni podría apelar a estos para alterar, en algún sentido, el contenido mismo de la relación laboral.

El criterio empleado para tan radical distinción obedecía a dos factores. Por un lado, a la concepción clásica de los derechos fundamentales como derechos públicos subjetivos, es decir, oponibles únicamente frente al Estado y no ante particulares; por otro, el carácter privado de la relación laboral, en cuyo seno no cabe, por consiguiente, que las partes invoquen sus derechos fundamentales para influir sobre la conformación de dicha relación, la cual debe regirse exclusivamente por la autonomía privada, con las ya indicadas limitaciones provenientes de las normas laborales heterónomas, constitucionales y legales ${ }^{10}$.

Esta dicotomía comenzó a ser superada por la doctrina alemana del Drittwirkung: la vigencia horizontal de los derechos constitucionales.

\section{EFICACIA VERTICAL Y HORIZONTAL DE LAS NORMAS CONSTITUCIONALES}

Las Cartas primigenias tienen como motor espiritual la exaltación del ser humano y sus derechos, por oposición y hasta en contraste con el poder político encarnado en el Estado. Aquello que Schmidt denomina "principio fundamental de distribución: una esfera de libertad del individuo, ilimitada en principio, y una posibilidad de injerencia del Estado, limitada en principio, mensurable y controlable"; para concluir en que "Los derechos fundamentales en sentido propio son, esencialmente, derechos del hombre individual libre, y por cierto, derechos que él tiene frente al Estado"11.

El principal problema que se enfrentó en un inicio fue determinar si tales derechos son vinculantes entre particulares, vale decir, si son exigibles en las relaciones jurídicas privadas, que se entablan por lo general dentro de los principios de libertad de contratación y autonomía de la voluntad.

\footnotetext{
10 Blancas Bustamante, Carlos. Derechos fundamentales de la persona y relación de trabajo. Lima, Perú: Fondo Editorial de la Pontificia Universidad Católica del Perú, 2007, p.15.

11 SCHMIDT, Carl. Teoria de la Constitución. Madrid, España: Alianza Editorial, 1982, p. 170.
} 
La respuesta tradicional del Derecho Constitucional a esta cuestión fue negativa. La teoría de los derechos fundamentales como "derechos públicos subjetivos", formulada por Jellineck atribuye a estos derechos la función de definir y garantizar la posición del individuo ante y en el Estado, configurando un status libertatis.

Los derechos públicos subjetivos son, según esta concepción, los que corresponden a toda persona como miembro del pueblo del Estado y que le aseguran el respeto y protección de sus libertades ante el poder de este, operando como un límite al mismo y garantía del estatus reconocido a la persona en su relación con el Estado. Por ello, esos derechos además de subjetivos, como lo es todo derecho, son "públicos" en cuanto a través de ellos se define la relación jurídica entre el individuo y el Estado ${ }^{12}$.

Esta concepción restringía el ámbito de actuación o eficacia de los derechos fundamentales al campo de las relaciones de derecho público, excluyendo aquellas que tienen su origen, y están reguladas, por el derecho privado, como es el caso de la relación de trabajo.

El cambio más importante provino de la doctrina (Nipperdey) y la jurisprudencia alemanas que introdujeron la noción de la Constitución como verdadero fundamento de la totalidad del ordenamiento jurídico, lo que implica la:

“(..) subordinación de todas las ramas del derecho, tanto público como privado, a aquella, que hoy día, especialmente a través de la vasta enumeración de derechos que contiene, establece los principios y bases de los ordenamientos normativos sectoriales o específicos. De este modo, aquellos ámbitos tradicionalmente reservados al derecho privado se encuentran hoy insertos dentro del marco general de la Constitución como norma fundante del ordenamiento en su conjunto, sin que el carácter privado de las relaciones que aquel regula pueda oponerse válidamente a la vigencia en éstas de las normas constitucionales. Ello no conduce, desde luego, a negar o devaluar el principio de la autonomía de la voluntad como fuente de estas relaciones, toda vez que la Constitución no contiene -ni puede hacer una regulación exhaustiva del derecho privado, como sí la tiene respecto de la organización de los poderes públicos- sino, únicamente, los trazos esenciales de éste, lo que, sin embargo, es suficiente para insertar en las relaciones de su ámbito el Principio de Supremacía de la Constitución y del mayor valor de los derechos fundamentales"13.

Algunos autores han destacado el hecho de que los derechos laborales en general, y sin duda también los consagrados a nivel constitucional, están diseñados para controlar el poder empresarial ante su eventual abuso.

"El régimen de libertades, derechos y principios constitucionales lleva ineludiblemente asociado a un sistema de límites a los poderes empresariales, de entre los cuales la primacía indiscutible la ocupan los derechos fundamentales. En un ordenamiento

12 JELLINECK, George. Teoría General del Estado. Madrid, España: Fondo de Cultura Económica, 2000, p. 387.

13 Fernandez SEGADO, Francisco. La dogmática de los derechos humanos. Lima, Perú: Ediciones Jurídicas, 1994 , pp. 62 y ss. 
pluralista (...), los derechos fundamentales se erigen en límites infranqueables que al empresario no le es dable desconocer en uso de su poder de dirección" 14 .

Y es que el reconocimiento actual de la "eficacia horizontal" de los derechos fundamentales entre particulares - y no solo frente al Estado en lo que se denomina "eficacia vertical"- conlleva la posibilidad de exigir el respeto de los mismos en cualquier ámbito o lugar, en tanto se permite que todos los particulares reclamen el ejercicio de los derechos reconocidos a nivel constitucional a terceros, ya sean estos poderes públicos o privados.

En esa línea, Carrillo Calle precisa que la "eficacia horizontal de los derechos fundamentales en las relaciones entre privados se deriva del concepto de Constitución como "Ley Fundamental de la Sociedad", que en el ordenamiento peruano se encuentra plasmado a través del artículo $1^{\circ}$ de la Constitución de 1993, que pone énfasis en señalar que "La defensa de la persona y el respeto de su dignidad son el fin supremo de la sociedad y del Estado", y reafirma, asimismo, la eficacia horizontal de los derechos fundamentales en todos sus alcances del precepto establecido en el ya citado artículo $38^{\circ}$ de la Carta Magna ${ }^{15}$.

Ello en razón de que el campo laboral es -y ha sido siempre- el más propicio para el desarrollo de estas nuevas corrientes, puesto que la relación laboral es desigual, con una parte dotada de grandes poderes, que se traducen en deberes para la contraparte.

"La relación laboral en que un empleador manda y un trabajador obedece otorga al primero, en tanto jefe, facultades o poderes jurídicos para ordenar y dirigir la prestación contratada y, al segundo, en tanto subordinado, el deber de cumplir dichas órdenes. Se trata de un poder privado para dirigir el trabajo; un poder jurídico sobre la persona del trabajador sólo referida a la correcta realización del trabajo y no extensible a otros aspectos de la vida del trabajador, pues incluso respecto de la ejecución del trabajo no es ilimitado, ya que debe detenerse allí donde empiezan los derechos que en tanto persona detenta el trabajador. En consecuencia, el sometimiento remunerado a la autoridad de un empleador para ganarse la vida no impide, limita ni atenúa los derechos fundamentales del trabajador.

En concordancia con lo precedentemente expuesto, es importante poner de manifiesto que será sobre todo en el plano laboral donde el tema de la eficacia de los derechos fundamentales cobrará una vigencia mayor, lo que se explica, porque la relación

14 VALDES DALRE, Fernando. "Poderes del empresario y derechos de la persona del trabajador", en: Revista Relaciones Laborales. La Ley - Actualidad. Tomo I. Madrid, 1990, p. 281.

15 La jurisprudencia del Tribunal Constitucional del Perú, a partir de la norma contenida en el artículo $38^{\circ}$ de la Constitución de 1993, según la cual "Todos los peruanos tienen el deber (...) de respetar, cumplir (...) la Constitución (...)", ha sentado la doctrina de que: "Esta norma establece que la vinculatoriedad de la Constitución se proyecta erga omnes, no solo al ámbito de las relaciones entre los particulares con el Estado, sino también a aquellas establecidas entre particulares. De manera que la fuerza normativa de la Constitución, su fuerza activa y pasiva, así como su fuerza reguladora de las relaciones jurídicas, se proyecta también a las establecidas entre particulares, por lo que cualquier acto proveniente de una persona natural o persona jurídica de derecho privado, que pretenda conculcarlos o desconocerlos, deviene inexorablemente en inconstitucional". (Fundamento No 5 de la Sentencia del Tribunal Constitucional de 13 de marzo de 2003, Exp. 976-2001-AA/TC, Eusebio Llanos contra Telefónica del Perú). 
laboral posee un elemento particular que la diferencia de las otras relaciones jurídicas entre particulares, cual es, el vínculo de subordinación del trabajador frente a su empleador, de lo que se deriva que el empleador detenta un poder particular frente al trabajador de dirección y control, que es reconocido y amparado por el propio sistema jurídico. Se rompe, entonces, la posición de equivalencia presente en las demás relaciones jurídicas de Derecho Privado por la existencia de un elemento de jerarquía entre el trabajador subordinado y su empleador que es más bien propio de las relaciones de Derecho Público. Además, este elemento esencial de la relación jurídica laboral va a ser precisamente el punto de partida de las tensiones entre el reconocimiento de los poderes del empresario y de los derechos fundamentales del trabajador, en cuanto persona y ciudadano, en el ámbito concreto de la empresa"16.

\section{Como sintetiza Blancas ${ }^{17}$ :}

"La extensión de la eficacia de los derechos fundamentales a las relaciones entre particulares se vislumbra, de este modo, como un límite efectivo frente a la arbitrariedad privada, al sujetar las relaciones entre sujetos privados a reglas y límites jurídicos, de forma similar a los límites que el orden jurídico impone al poder del Estado con el fin de impedir el abuso del poder.

Por consiguiente, aunque no pretende suprimir el principio de la autonomía de la voluntad, la eficacia horizontal, sí le impone límites y marcos dentro de los cuales este debe desenvolverse respetando los derechos fundamentales de las partes, toda vez que la libertad de contratación, que es un derecho fundamental, no puede erigirse en un derecho superior a los demás derechos fundamentales, ni, por lo mismo, ejercerse en desmedro de estos" 18 .

Llegados a este punto, señala el mismo autor" ${ }^{19}$ que, "hay derechos que solo tienen sentido en la relación individuo-Estado y no son, en modo alguno, aplicables a las relaciones trabajador-empleador". Sin embargo, existen otros que "(...) tienen su vertiente laboral, en el sentido de que pueden emerger u ocurrir, y aún ocurrir con manifestaciones típicas, en conexión con las relaciones individuales y colectivas de trabajo", como lo señaló Alonso Olea. En el mismo sentido, Palomeque indicará que, además de los derechos laborales,

“(...) otros derechos constitucionales de carácter general y, por ello, no específicamente laborales pueden ser ejercitados, sin embargo, por los sujetos de las relaciones de trabajo (los trabajadores en particular) en el ámbito de las mismas, por lo que en tal caso adquieren un contenido o dimensión laboral sobrevenidos. Se produce así

\footnotetext{
16 CaAmaño Rojo, Eduardo. "La eficacia de los derechos fundamentales en las relaciones laborales", en: Revista de Derecho de la Pontificia Universidad Católica de Valparaíso, vol. XXVII, semestre I 2006, pp. 20-21.

17 Blancas Bustamante, Carlos, op. cit. (n. 10), p. 36.

18 Ibid.

19 Citado por Blancas BustamanTe, Carlos, op. cit. (n. 10), p. 89.
} 
una "impregnación laboral" de derechos de titularidad general o inespecífica por el hecho de su utilización por trabajadores asalariados (también eventualmente por empresarios) a propósito y en el ámbito de un contrato de trabajo ${ }^{20 "}$.

La extensión o expansión de los derechos fundamentales al espacio de las relaciones privados es, pues, el campo de cultivo y el prerrequisito para la aparición de los derechos inespecíficos. Como señala Caamaño:

“(...), la noción de ciudadanía en la empresa surge a partir del reconocimiento jurisprudencial, doctrinal y legal de que la empresa no es un espacio entregado única y soberanamente al ejercicio de los poderes empresariales, sino que es un ámbito en el que también tiene cabida y pleno reconocimiento la ciudadanía de los sujetos que interactúan en este especial ámbito de la vida social, esto es, la aceptación de la titularidad de un conjunto de derechos fundamentales emanados de su condición de persona, particularmente, derechos civiles y políticos que, en cierta forma, quedaban amagados en la relación de trabajo, ya sea por la necesidad de una mejora urgente de las condiciones económicas y de trabajo o por efecto de la exacerbación de la potestad de mando del empleador. Así, entonces, la conversión de los derechos fundamentales de contenido no laboral (v.gr. libertad de expresión, derecho a la igualdad de trato y a la no discriminación, libertad religiosa, etc.) en verdaderos derechos fundamentales laborales tiene lugar por una doble y simultánea vía: por una parte, en cuanto son trabajadores los sujetos a los que corresponde la titularidad del derecho y, por otra, porque el derecho se ejerce en una relación jurídica laboral ${ }^{21}$ ".

\section{LOS DERECHOS LABORALES INESPECÍFICOS}

Los derechos fundamentales laborales han sido reconocidos desde una doble perspectiva: ya que, en cuanto a los trabajadores, es a estos a quienes corresponde la titularidad del derecho y debido a que el derecho se ejerce en una relación jurídica laboral.

La Constitución, como norma fundamental de un Estado de Derecho, es ley suprema y factor principal de la organización de todo el ordenamiento jurídico en tanto que presenta la interacción de las fuentes del derecho con las reglas básicas de articulación de las mismas, así como reconoce los derechos y deberes fundamentales de los individuos y de los grupos sociales.

La Constitución, que no quiere ser un ordenamiento neutral, ha introducido con los derechos fundamentales un ordenamiento valorativo objetivo, en el cual se encuentra la más importante consolidación de la fuerza de validez de aquellos. Este sistema de valores, que encuentra su punto central en el libre desarrollo de la personalidad y en la dignidad del ser humano, vale como una decisión constitucional fundamental para todos los ámbitos del

20 Blancas Bustamante, Carlos, op. cit. (n. 10), p. 89.

21 CaAmaño Rojo, Eduardo, op. cit. (n. 16), p. 27. 
derecho: legislación, administración y jurisdicción reciben de ella sus líneas orientativas y su impulso 22 .

Los derechos y principios laborales reconocidos en la Constitución tienen "su origen o razón de ser exclusiva o principalmente en el ámbito de las relaciones laborales, de modo que es imposible técnicamente su ejercicio fuera de las mismas. La relación de trabajo se convierte así en presupuesto absoluto de su perfeccionamiento y ejercicio". Estamos ante "derechos constitucionales específicamente laborales" (derechos específicos), de los cuales son titulares los trabajadores asalariados (...) en tanto son sujetos de una relación laboral ${ }^{23}$.

Pero otros derechos constitucionales de carácter general, y no específicamente laborales, pueden igualmente ser ejercitados por y entre los sujetos de las relaciones de trabajo. Son derechos de carácter general, atribuidos a todos los ciudadanos y que son ejercitados por ellos dentro de una relación laboral. Son ciudadanos que, al mismo tiempo y naturalmente son trabajadores $y$, por lo tanto, esos derechos que en su origen no son estrictamente laborales se convierten en derechos laborales por razón de los sujetos y de la naturaleza de la relación jurídica en que se ejercen. Son "derechos del ciudadano trabajador, a fin de cuentas, que ejercita como trabajador ciudadano"24.

Los derechos constitucionales laborales inespecíficos enunciados por Palomeque son aquellos que Alonso Olea denominaba la versión laboral de los derechos fundamentales y libertades públicas, tratando de resaltar con ello la existencia de un "Derecho Constitucional del Trabajo"25. Para Valdés Dal Ré, tanto los derechos laborales específicos como los inespecíficos forman el marco normativo de las relaciones de trabajo y son a su vez limitantes para el poder empresarial. "El poder empresarial que se apoya en la subordinación del trabajador por el contrato de trabajo puede llegar a convertirse en un peligro para el ejercicio de las libertades del trabajador, por ello la Constitución como norma fundamental y la legislación laboral van dirigidas especialmente a controlar dicho poder" 26 .

Por eso las Constituciones traen ahora declaraciones como la de la peruana, según la cual "Ninguna relación laboral puede limitar el ejercicio de los derechos constitucionales, ni desconocer o rebajar la dignidad del trabajador (artículo $23^{\circ}$, segundo párrafo). "Es a partir de esta premisa impuesta por la Constitución que debe abordarse toda controversia surgida en las relaciones jurídicas entre empleador y trabajador, en todo momento: al inicio, durante y al concluir el vínculo laboral"27.

\footnotetext{
22 Fundamento No 5 de la Sentencia del Tribunal Constitucional del Perú de 13 de marzo de 2003, Exp. 976-2001-AA/TC, Eusebio Llanos contra Telefónica del Perú.

23 Palomeque López, Manuel-Carlos. Los derechos laborales en la Constitución española. Madrid, España: Centro de Estudios Constitucionales, 1991, pp. 31-32.

24 Carrillo Calle, Martín. Apuntes de clase, 2004.

25 Alonso Olea, Manuel. Las Fuentes del Derecho, en especial del Derecho del Trabajo según la Constitución. $2^{\mathrm{a}}$ Edición. Madrid, España: Editorial Civitas, 1990.

26 VAldes DalRE, Fernando, op. cit. (n. 14), p. 281.

27 Fundamento No 6 de la Sentencia del Tribunal Constitucional de 11 de julio de 2002, Exp. 1124-2001-AA/TC, Sindicato Unitario de Trabajadores de Telefónica del Perú S.A. y Fetratei contra Telefónica del Perú S.A. y Telefónica Perú Holding S.A.
} 
Señalan Palomeque López y Álvarez de la Rosa ${ }^{28}$ que los derechos específicos laborales tienen:

“(...) su origen específico o razón de ser (exclusiva o principalmente) en el ámbito de las relaciones laborales, de modo que no es posible técnicamente su ejercicio fuera de las mismas. La relación de trabajo, activa o como referencia pretérita o de futuro, se convierte de este modo para aquellos en presupuesto insoslayable de su nacimiento y ejercicio"”

A ello añaden que los derechos laborales inespecíficos son:

"otros derechos constitucionales de carácter general y, por ello, no específicamente laborales (que) pueden ser ejercidos, sin embargo, por los sujetos de las relaciones de trabajo (los trabajadores, en particular) en el ámbito de las mismas, por lo que en tal caso adquieren un contenido o dimensión laborales sobrevenidos. Se produce una "impregnación laboral" de derechos de titularidad general o inespecífica por el hecho de su ejercicio por trabajadores asalariados (también eventualmente por empresarios) a propósito y en el ámbito de un contrato de trabajo".

Como expresa con su claridad y lucidez características el inolvidable maestro Óscar Ermida Uriarte ${ }^{29}$ :

"Está claro que la titularidad y goce de tales derechos (universales, irrenunciables e indisponibles ), mal podrían verse afectados por la celebración de un contrato de trabajo o por la incorporación a una unidad productiva jerarquizada, como la empresa. Como alguna vez bien dijo Romagnoli, al ingresar a la fábrica, el trabajador no deja colgados en la reja, junto a su gorra, los derechos humanos de que es titular, ni los guarda en el ropero del vestuario, junto a su abrigo, para retomarlos al fin de la jornada. Por el contrario, él sigue siendo titular de los derechos esenciales a todas las personas, como el derecho a la dignidad, al honor, a la intimidad, a las libertades de pensamiento y de cultos, a la libre expresión del pensamiento, etc.), los que vienen, por tanto, a engrosar significativamente el número de derechos humanos de que es titular el trabajador.

Esta ampliación de los derechos humanos laborales no respondió a una reforma constitucional ni a la adopción de nuevas normas internacionales. Respondió, simplemente, a una nueva lectura de las mismas normas ya existentes. Fue una creación doctrinal y jurisprudencial, originada en Europa y luego extendida en América latina y en Uruguay".

28 Palomeque, Manuel Carlos y Álvarez de la Rosa, M., op. cit. (n. 3), p. 147.

29 ERMIDA URIARTE, Óscar. "Derechos humanos laborales en el derecho positivo uruguayo", en: BARRETO GHIONE, Hugo. Investigación sobre la aplicación de los principios y derechos fundamentales en el trabajo en Uruguay. Organización Internacional del Trabajo, Lima, 2006, p. 14. 
A lo que añade:

"Estos derechos inespecíficos -denominados a veces "derechos de la persona del trabajador" y otras veces presentados en el concepto de "ciudadanía en la empresa" - tienen diversas significaciones. En primer lugar $-\mathrm{y}$ a ello alude la primera de las denominaciones citadas-, amplía la esfera personal de autonomía del trabajador. En segundo término -y a ello alude la segunda de las denominaciones-, recuerda que el trabajador es también un ciudadano y apunta a democratizar ese espacio de poder y dominación que es la empresa, y a cuya extensión y profundización había contribuido tanto el contrato de trabajo, atribuyéndose efectos que excedían en mucho la esfera de lo jurídicamente disponible. $Y$ en tercer lugar, es del caso señalar cómo han dado fundamento al surgimiento de nuevos derechos, a la extensión y reelaboración de otros de no poca importancia o a la imposición de nuevos límites a las facultades patronales, tales como, por ejemplo, y sin ninguna pretensión de exhaustividad, la proscripción de los acosos sexual y moral, la limitación de medidas de revisión física del trabajador y de otras medidas de control, como las audiovisuales, la afirmación y extensión de la intimidad y de la libertad en la vestimenta y en la apariencia física, etc." 30 .

La breve enunciación de Ermida lleva a una pregunta crucial: ¿cuáles son, en concreto, los derechos laborales inespecíficos?

\section{LOS DERECHOS LABORALES INESPECÍFICOS EN CONCRETO}

No hay, por cierto, y difícilmente podría haber un catálogo de derechos inespecíficos. pecíficos son:

Sagardoy ${ }^{31}$, siguiendo a Palomeque, entiende que los derechos constitucionales ines-

- $\quad$ El derecho a la igualdad y no discriminación (...) (arts. 14 y $35.1 \mathrm{CE}$ ), recibido en la legislación laboral por los artículos 4.2.c) y 17 ET;

- La libertad ideológica y religiosa, por la que nadie pueda ser obligado a declarar sobre su "ideología, religión o creencias" (art. 16.1 CE). Tampoco, ciertamente, los trabajadores a revelar su afiliación sindical ("no puede abrigarse duda alguna de que la afiliación a un sindicato es una opción ideológica protegida por el art. 16 CE”, STC 94/1998; lo que deja de ser un derecho "personal y exclusivo del trabajador", que están obligados a respetar, tanto el empresario como los propios órganos sindicales (SSTC 292/1993 y 94/1998);

$\mathrm{El}$ derecho al honor, a la intimidad personal y a la propia imagen (art. 18.1 CE) y, en el ámbito de la relación laboral, derecho de los trabajadores "al respecto de su intimidad y a la consideración debida a su dignidad, comprendida la protección frente a ofensas

30 Ibid., p. 15.

31 SAGARDOY BengoeCheA, Juan A. Los derechos fundamentales y el contrato de trabajo. Madrid, España: Thomson Civitas, Cuadernos Civitas, 2005, pp.14 y ss. Lo recogido entre paréntesis o entre comillas corresponde, como es natural, a la Constitución (CE) y legislación españolas. 
verbales o físicas de naturaleza sexual y frente al acoso por razón de origen racial, étnico, religioso, convicciones, discapacidad, edad u orientación sexual (art. 4.2 e) ET);

- La libertad de expresión o derecho a "expresar y difundir libremente los pensamientos, ideas y opiniones mediante la palabra, el escrito o cualquier otro medio de reproducción" (art. $2^{\circ} .1$ a) CE), recogida de modo expreso por la legislación laboral, tan solo como garantía de los representantes de los trabajadores en la empresa, que podrán "expresar, colegiadamente, si se trata del comité, con libertad, sus opiniones en las materias concernientes a la esfera de su representación (art. $68 \mathrm{~d}$ ) ET);

La libertad de información, esto es, el derecho a "comunicar o recibir libremente información veraz por cualquier medio de difusión" (art. $20.1 \mathrm{~d}$ ) $\mathrm{CE}$ );

El derecho de reunión (art. $21 \mathrm{CE}$ ), proyectado al ámbito de las relaciones laborales por los artículos 4.1.f (los trabajadores tienen como derecho básico el de "reunión") y 77 a 80 (el derecho de los trabajadores de una misma empresa o centro de trabajo a "celebrar reuniones, previa notificación al empresario" en la empresa o centro de trabajo);

El derecho a la tutela judicial efectiva (art. $24 \mathrm{CE}$ ), recogido por el ordenamiento jurídico laboral en los artículos 4.2.g) (el derecho de los trabajadores al "ejercicio individual de las acciones derivadas de su contrato de trabajo) y 65.1 (el ejercicio de acciones judiciales por órganos de representación de los trabajadores en la empresa) ET y en la LPL;

El derecho a no ser sancionado por acciones $u$ omisiones que en el momento de producirse no constituyan delito, falta o infracción administrativa, según la legislación vigente en aquel momento (art. 25.1 CE), o principio de legalidad (art. 9.3 CE), ejercitable también, naturalmente, por los distintos sujetos responsables de infracciones administrativas en el orden social, los empresarios, en particular (L 5/2000, sobre infracciones $y$ sanciones de orden social);

- El derecho a la educación (art. 27.1 CE), aun cuando no pueda imponerse al empresario "la obligación de satisfacer de manera incondicionada la pretendida compatibilidad de la asistencia a clases del trabajador o empleado con el cumplimiento de las obligaciones derivadas de la relación de dependencia", ya que, entenderlo así, "sería tanto como desplazar sobre el empleador la carga prestacional del derecho a la educación, que solo sobre los poderes públicos pesa, y hacer responsable a aquel del deber positivo de garantizar la efectividad del derecho fundamental que solo a estos corresponde" (STC 129/1989).

Blancas $^{32}$, sin apartarse demasiado de esta enumeración, agrega sin embargo dos importantes derechos: al secreto e inviolabilidad de las comunicaciones privadas y a la integridad moral y psíquica de la persona humana.

Acota al respecto, el propio Sagardoy, algo sumamente importante: 
"Conviene precisar que tal elenco de derechos, salvo el de reunión y el de educación, son igualmente predicables de la otra parte o sujeto del contrato de trabajo: el empleador. El análisis de los derechos fundamentales en el seno del contrato de trabajo sufre en la corta historia de su tratamiento doctrinal -las sentencias del TC han hecho a veces referencia al tema- de un sorprendente unilateralismo y metodología agresiva, puesto que solo se hace referencia a los derechos fundamentales del trabajador, no también, del empleador y con enfoque de agresión o violación de los derechos de los trabajadores por parte de los empleadores y no, con una mayor neutralidad, de violación también a la inversa. Es decir, se echa en falta un enfoque de normalidad o neutralidad, en cuanto a la dinámica de esos derechos fundamentales en la relación laboral. ¿O es que el empleador, como sujeto de un contrato de trabajo, no tiene derecho al honor?

\section{A MODO DE CONCLUSIÓN}

1.- Los derechos humanos están colocados hoy en el vértice de los instrumentos internacionales y forman parte esencial del contenido de las modernas Constituciones.

Algunos de esos derechos fundamentales son de contenido netamente laboral, otros no. Hay también, obviamente, derechos laborales que no alcanzan rango o categoría de fundamentales. Pero hay un elenco sumamente importante de derechos que son al mismo tiempo fundamentales y laborales, como el derecho a una limitación de la jornada de trabajo, el derecho a los descansos, la protección contra el despido arbitrario y, naturalmente, la libertad sindical y el derecho de negociación colectiva.

2.- Los principios y normas sobre derechos humanos constituyen un bloque de la más alta jerarquía y fuerza normativa, tanto a nivel supranacional cuanto constitucional.

3.- Si bien las Constituciones fueron primigeniamente entendidas como la exaltación del ser humano y sus derechos frente al poder político, a partir de la doctrina alemana se asumió que tenían fuerza también en las relaciones entre particulares. La Constitución, como norma fundante de la sociedad, no agota su eficacia en la relación vertical entre el ciudadano y el Estado, sino que la tiene también para regular en forma horizontal las relaciones entre particulares.

4.- La eficacia horizontal de las normas constitucionales y de los derechos fundamentales asume especial importancia en el campo laboral, habida cuenta de que el empleador ejerce poderes que mutatis mutandis se asemejan a los que ejerce el Estado frente a los ciudadanos.

5.- Existen derechos laborales identificados y reconocidos como tales en los instrumentos internacionales y en los textos constitucionales. No son ellos, empero, los únicos que corresponde reconocer a los trabajadores en su relación con el empleador, Hay dere- 
chos que corresponden a los trabajadores en tanto que ciudadanos, y que pueden ser exigidos al interno de la relación laboral.

Son derechos laborales inespecíficos, en la feliz expresión de Manuel Carlos Palomeque, que ha adquirido carta de ciudadanía. "La titularidad y goce de tales derechos -dice Ermida- mal podrían verse afectados por la celebración de un contrato de trabajo o por la incorporación a una unidad productiva jerarquizada, como la empresa."

6- No existe un elenco o catálogo cierto de tales derechos inespecíficos laborales. La propuesta inicial de Palomeque, recogida por Sagardoy, puede constituir una pauta certera. En tal línea, los derechos inespecíficos laborales más relevantes son:

- Derecho a la igualdad y no discriminación;

- Libertad ideológica y religiosa;

- Derecho al honor, a la intimidad personal y a la propia imagen;

- Libertad de expresión;

- Libertad de información;

- Derecho de reunión;

- Derecho a la tutela judicial efectiva;

- Derecho a no ser sancionado por acciones u omisiones que en el momento de producirse no constituyen delito, falta o infracción;

- Derecho a la educación.

7.- Al elenco propuesto bien podrían añadirse los derechos sugeridos por Blancas: el secreto e inviolabilidad de las comunicaciones privadas, y el derecho a la integridad moral y psíquica de la persona del trabajador.

Lima/Bogotá, febrero 2012. 